\title{
Normalizing physiological data for scleractinian corals
}

Received: 22 June 2001 / Accepted: 23 September 2001 / Published online: 26 April 2002

(C) Springer-Verlag 2002

Keywords Coral $\cdot$ Scleractinia $\cdot$ Physiology ·

Normalizing

\section{Introduction}

Increasing body size exposes the structural, functional, and geometric constraints of phenotype design (Schmidt-Nielsen 1984) which result in scaling effects that have a pervasive and profound influence on organismic physiology (Gould 1966; Schmidt-Nielsen 1984). In experimental research, the confounding effects of size (i.e., scaling) can be minimized by comparing organisms of similar size, or by comparing organisms of different size after normalizing the results to a metric that reflects size. Size normalization assumes a proportional relationship (i.e., isometry) between size and the trait of interest (Packard and Boardman 1988), yet the assumption of isometry is rarely demonstrated and most traits scale disproportionately with size (i.e., allometry). Isometry characterizes only a small number of taxa, and includes the colonial modular organisms like bryozoans (Hughes and Hughes 1986) and, theoretically, the scleractinian corals (Jackson 1979; Sebens 1987).

Corals present a number of problems for normalization of physiological data. Their tissue biomass (i.e., size) is difficult to quantify due to its gelatinous and contractile nature, and the tissues are closely intertwined with a morphologically complex skeleton. Although tissue area can serve as a proxy for biomass in isometric

\section{P.J. Edmunds ( $\square)$}

Department of Biology, California State University,

18111 Nordhoff Street, Northridge,

California 91330-8303, USA

E-mail: peter.edmunds@csun.edu

Tel.: + 1-818-6772502

Fax: + 1-818-6772034

R.D. Gates

Department of Organismic Biology, Ecology and Evolution, University of California, 621 Charles E. Young Drive South, Los Angeles, California 90095-1606, USA organisms, in corals the actual tissue area varies with polyp expansion, and this, in turn, is plastic and highly responsive to environmental conditions. Faced with these problems, early coral physiologists normalized their results by colony (e.g., rate/colony; Yonge et al. 1932), or by weight of the entire colony (e.g., rate/g coral; Kawaguti 1937), so that colonies of equivalent shape, weight, and density could be compared. In rare cases, individual polyps have been used for normalizing (e.g., rate/polyp; Marshall 1996), but the diversity of polyp and corallite dimensions (Porter 1976), interspecific variation in polyp density (Clayton 1985), and plastic corallite morphology (Bruno and Edmunds 1997) restricts useful comparisons to species with conserved corallite dimensions and densities. Presently, the two most common size-normalizing parameters for scleractinian corals are the surface area of the skeleton covered by living tissue, and tissue biomass. Here we revisit the question of which normalizing parameter is most suitable for studies of coral physiology, and suggest that biomass is often more appropriate than surface area for this purpose.

The surface area of the skeleton has been used to standardize physiological data for $>60$ years (e.g., Motoda 1940; Kanwisher and Wainright 1967), but it gained widespread acceptance with the publication of the simple "aluminum foil" method (Marsh 1970). Although alternative techniques such as dye-dipping (Hoegh-Guldberg 1988) provide greater resolution for morphologically complex skeletons, none of the available methods quantifies the actual area of coral tissue, which arguably is more biologically relevant than skeletal area in normalizing the flux of important solutes (Patterson 1992). Coral tissue conforms closely to the surface of the skeleton, and sometimes penetrates the outer layer of the skeleton to a depth of several millimeters (e.g., Porites), but there is no clear relationship between skeletal area and actual tissue area. The actual tissue area is determined by the instantaneous area of polyps and tentacles, and therefore varies hugely depending on the degree of contraction. Normalizing to 
biomass avoids having to equate skeleton area to actual tissue area, but the common practice of treating biomass and area-normalized data as equivalent (Edmunds and Davies 1986) is misleading if biomass varies.

A substantial hurdle to quantifying coral biomass is the separation of living tissue from dead skeleton. One approach is to dissolve the skeleton in acid and quantify the organic content of the slurry, for example as total nitrogen content (Goreau and Goreau 1959). If the tissue is fixed prior to decalcification, biomass can be determined by drying and weighing the tissue tunic remaining (Davies 1980). Regardless of the analytical technique, the unpleasant task of decalcification deterred the use of biomass for normalizing until alternative techniques were developed. Such techniques involve using a jet of high-pressure water from a dental hygiene tool (a WaterPik ${ }^{\circledR}$; Johannes and Wiebe 1970), or a jet of compressed air and water from an artist's air brush, to blast the tissue off the skeleton (e.g., Szmant et al. 1990). The WaterPik ${ }^{\circledR}$ provides a quantitative tool for the removal of coral tissue in a slurry suitable for proximal analysis including, for example, the quantification of biomass as protein content. The effectiveness of the WaterPik ${ }^{\circledR}$ in removing coral tissue varies depending on the perforate nature of the skeleton of the coral species. However, WaterPik ${ }^{\circledR}$ is the method of choice for the majority of researchers, and in our hands we have obtained $>92 \%$ efficiency using this tool to remove zooxanthellae from the perforate coral Porites porites (Edmunds 1994). This suggests that the majority of the coral tissue is removed, assuming that the zooxanthellae provide an effective proxy for coral tissue, a condition that is likely to be correct where the zooxanthellae are distributed uniformly throughout the tissue.

The suite of analytical techniques employed by coral physiologists has advanced significantly in the last decade. For instance, while simple photosynthesis to respiration ratios provided insight into coral physiology in the 1960s and 1970s (Beyers 1966; Wells et al. 1973), contemporary studies employ advanced techniques such as the analysis of protein expression (Black et al. 1995), metabolite concentration (Lesser et al. 1994), short-term biochemical dynamics (Brown et al. 1999a), and the intracellular microenvironment (Kühl et al. 1995). Given the precision and dynamic nature of these measures, it is essential to normalize to a parameter that accurately reflects the size of the animal on a temporally relevant scale. In this context, we examine the suitability of the surface area of the skeleton and soluble protein as biologically relevant metrics for normalizing physiological data in scleractinian corals.

To support our discussion, we draw upon data originally collected for different purposes. First, we present data from a manipulative experiment with Montastraea franksi that demonstrates differing results for area-normalized versus protein-normalized data. This experiment was completed in Jamaica during January 1994, with the goal of comparing bleaching susceptibility among coral clones. Second, we use results from a mensurative experiment with $M$. franksi to demonstrate a disproportionate relationship between zooxanthella content normalized to area and protein, and variable protein content among adjacent conspecifics. This experiment was completed in the Florida Keys during August 1997 and July 1998, with the initial goal of quantifying the characteristics of coral tissue during a natural bleaching event.

\section{Methods}

The manipulative experiment compared bleaching between clones of $M$. franksi transplanted from deep to shallow water. Clonemates were prepared from two plates of $M$. franksi that were collected from 21-m depth on the fore reef at Discovery Bay. Each plate was broken into clone-mates (i.e., ramets of each genet) with a mean area of $12.0 \pm 0.6 \mathrm{~cm}^{2}( \pm \mathrm{SE}, n=32)$, and these were glued to tiles and returned to the collection depth. After 5 days of recovery, some ramets were kept at $21-\mathrm{m}$ depth as controls $(n=7 /$ genet $)$, and some were moved to $3-\mathrm{m}$ depth (transplants; $n=8-10 /$ genet) to induce bleaching. The protein content of the two clones was measured at the start of the experiment, and after 7 days the controls and transplants were collected and their area, protein, and zooxanthellae content were measured. Area was assessed with aluminum foil (Marsh 1970); zooxanthellae were quantified using a hemocytometer to count the cells in the tissue slurry removed with a WaterPik ${ }^{\circledR}$ (Johannes and Wiebe 1970) and concentrated by centrifugation. Soluble protein in the tissue slurry (i.e., of animal and algal origin) was measured using the Coomassie Brilliant Blue assay (Bradford 1976; Edmunds et al. 2001). Zooxanthella densities were normalized to the area and protein content of each ramet, and compared between clones and treatments with a mixed model, two-way ANOVA (clone $=$ random factor, treatment $=$ fixed factor). The residuals from the ANOVA were used to test the assumptions of normality and homoscedasticity, and we assumed that the ramets were statistically independent replicates of each genet because they were physiologically autonomous, and had recovered from the initial fragmentation. Protein content was compared between clones with a t-test.

The mensurative experiment quantified the effects of bleaching on $M$. franksi that was part of the widespread event coincident with the severe El Niño of 1997/1998. The study population was at $15-\mathrm{m}$ depth on Conch Reef, and was sampled at times coincident with a previously planned research trip (1997), and a time point approx. 1 year later (1998), respectively. Because the research trip was not specifically scheduled to quantify the effects of bleaching, we have no time-course data to determine when these corals first were affected by thermal stress, or how long they had been pale when we collected our first samples. In 1997, 75 colonies were selected haphazardly to assess bleaching severity, and the majority $(93 \%)$ was bleached. By July 1998, 23 of the same colonies were normally colored (i.e., khaki brown/green) and these are used in the present analysis to equate area and protein normalization in relatively "healthy" corals. Since these corals were sampled only 11 months after a severe bleaching event, and at a time when seawater temperatures again were unusually high (NOAA 2001), it is possible that recovery was incomplete, and that another bleaching event already was underway. Several Caribbean corals appear normally colored even when their zooxanthella populations are substantially reduced (Fitt et al. 2000), and in the present study the zooxanthella densities in $M$. franksi that were khaki brown/green in 1998 may have been depressed compared to normal densities. A fragment of skeleton and tissue was removed from the 23 colonies and processed immediately for area, zooxanthella densities, and protein content using the methods described above. Zooxanthella densities were normalized to area and protein, and tested for proportional variation using Model II regression and a t-test of the null hypothesis that $b$ (slope) corresponds to a doubling in zooxanthellae per milligram of protein for a doubling in the 
zooxanthellae per square centimeter. A histogram was used to examine the variability in protein content of the sampled colonies.

\section{Results and discussion}

The results of the manipulative experiment differed qualitatively in magnitude and direction depending on whether zooxanthellae were normalized to area or protein (Fig. 1). Zooxanthella densities were higher in controls for clone 1 versus clone 2 when normalized to protein, but not when normalized to area. Transplantation reduced zooxanthella densities in clone 1 but not in clone 2, regardless of the normalizing method. When normalized to area, there was a significant interaction of clone and treatment $(\mathrm{F}=5.763, \mathrm{df}=1,28, P=0.023)$ and no significant difference between clones $(\mathrm{F}=4.168$, $\mathrm{df}=1,28, P=0.051)$. The interaction of clone and treatment was highly significant when zooxanthella densities were normalized to protein $(\mathrm{F}=7.971, \mathrm{df}=1$, $28, P=0.009)$, and there was a significant difference between clones $(\mathrm{F}=4.993, \mathrm{df}=1,28, P=0.038)$. Thus, the normalizing method modified the interpretation of the experiment by strengthening the interaction between clone and treatment, and accentuating the difference between clones. These effects were probably a result of between-clone differences in protein content which, for the control corals (i.e., unstressed) was $0.22 \pm 0.03 \mathrm{mg} /$ $\mathrm{cm}^{2}$ for clone 1 and $0.33 \pm 0.06 \mathrm{mg} / \mathrm{cm}^{2}$ for clone 2 (both mean $\pm \mathrm{SE}, n=7$ and 8 , respectively). Protein content differed $50 \%$ between clones, but this difference was not statistically significant $(\mathrm{t}=1.695, \mathrm{df}=13, P=0.114)$.

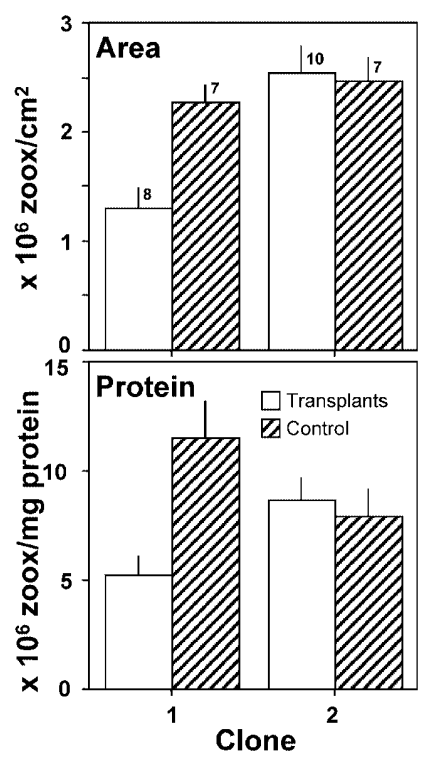

Fig. 1. Zooxanthellae content of two clones (1 and 2) of Montastraea franksi, clone mates of which either were kept at 21-m depth for 7 days (controls), or were transplanted from $21-\mathrm{m}$ depth to 3-m depth (transplants) for 7 days. Above Results normalized to surface area; below the same results normalized to protein content. Mean $\pm \mathrm{SE}$ is shown, with sample sizes above each bar. Refer to text for further details
The mensurative experiment demonstrated that zooxanthellae per square centimeter was correlated significantly with zooxanthellae per milligram of protein $(r=0.633, n=23, P=0.001$; Fig. 2$)$, but the slope of the relationship $(b=0.259)$ differed significantly from the slope necessary for proportional variation $(b=0.356$ and passing through the centroid, $\mathrm{t}=2.205, \mathrm{df}=21$, $P=0.039)$. Thus, there was disproportional variation in zooxanthella densities normalized to area and protein. For instance, a doubling in zooxanthellae per milligram of protein (from $1 \times 10^{6}$ to $2 \times 10^{6}$ ) corresponded only to a $60 \%$ increase in zooxanthellae per square centimeter (from $0.43 \times 10^{5}$ to $0.69 \times 10^{5}$ ) (Fig. 2a). The histogram showing the protein content for the same corals (Fig. 2b) reveals positive skewing and a four-fold difference between the extremes for colonies on the same reef. Variation in protein biomass can account for at least some of the discrepancies between the two methods of normalizing zooxanthellae, because the corals with the smallest biomass (filled squares in Fig. 2a) tend to depress the slope of the line relating zooxanthellae per square centimeter and zooxanthellae per milligram of protein. However, some of the variance in zooxanthella densities is independent of protein biomass, as shown by the similar ranges of zooxanthella densities (regardless of normalizing method) for the first two protein biomass size classes $\left(<0.4 \mathrm{mg} / \mathrm{cm}^{2}\right)$ and for the data set as a whole (Fig. 2b). Variation of zooxanthella densities within a range of protein biomass values could reflect differences in host cell size caused by, for example, varying lipid and carbohydrate content, and different numbers of zooxanthella within each cell (Muscatine et al. 1998). The discrepancy between area- and biomassnormalized results might also have been accentuated by protein losses associated with bleaching (Porter et al. 1989) that occurred in 1997, or were beginning in 1998.
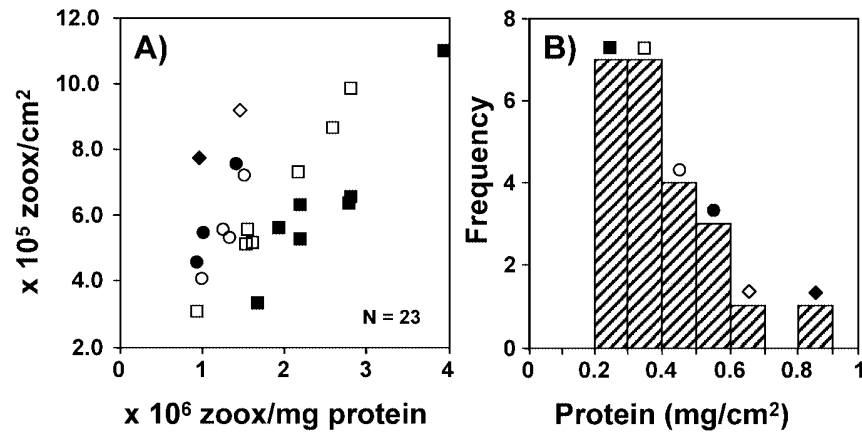

Fig. 2. a Zooxanthellae content of 23 colonies of Montastraea franksi at 15-m depth on Conch Reef in July 1998. Results are normalized to area and to protein, with the six symbols representing class intervals for protein content (shown in b). Overall (i.e., for pooled class intervals), there is a significant but disproportional relationship between zooxanthellae per milligram of protein and zooxanthellae per square centimeter (refer to text for further details). b Protein content of the 23 colonies of $M$. franksi that were analyzed for zooxanthellae content (a). The zooxanthellae content of the colonies belonging to each protein class interval are shown in a using the symbols shown above each bar of the histogram 
Regardless of the causes, the present data show that colony areas are not equivalent in terms of protein content, and that biomass can serve as a confounding covariate in comparisons based on area-normalized data. In the case of zooxanthella densities, normalizing to colony area obscures potentially important variation caused by differences in protein biomass as well as other factors, such as the packing of zooxanthella within host cells.

The value of area for normalizing coral physiology lies in the potential for valid comparisons independent of the confounding effects of size. Area is easy to measure and varies little during most experiments (i.e., changes in area due to growth are small), but its use in normalizing relies on two assumptions. First, it assumes that biomass does not vary over time, so that results from different periods can be compared directly. Although coral biomass is known to vary with water depth (Davies 1980; Lasker 1981), the common practice of comparing corals from similar depths at different sites using area-normalized data relies on biomass per area being similar at all sites. Second, area-normalization assumes that the colonial, modular design of most scleractinians provides freedom from allometric constraints (Jackson 1979). Thus, unlike unitary organisms (Schmidt-Nielsen 1974), the tissue biomass per unit area should be constant across a wide range of colony sizes. Several studies show that both of these assumptions are incorrect. For example, coral biomass and tissue thickness (a proxy for biomass) vary two-fold between winter and summer (Brown et al. 1999b; Fitt et al. 2000), and mean tissue thickness for Porites varies 2.3-fold among locations on the Great Barrier Reef (Barnes and Lough 1992). In addition, the assumption of isometric scaling for colonial scleractinians has been questioned based on theoretical analyses of mass transfer characteristics (Patterson 1992) and resource capture (Kim and Lasker 1998), as well as empirical studies of respiration and photosynthesis (Kim and Lasker 1998; Vollmer and Edmunds 2000). In 1985, W.S. Clayton reported 35\% difference in polyp density (polyps/ $\mathrm{cm}^{2}$ ) between colonies of Pocillopora damicornis growing at the same depth, and drew attention to the need to understand this variation in order to advance the field of coral energetics (Clayton 1985). In more than 15 years, little attention has been paid to variation in biomass per area of skeleton (but see Brown et al. 1999b; Fitt et al. 2000), and coral physiologists still normalize their data to area or biomass without addressing the assumptions implicit in their choice of normalizing parameter. Although we have used zooxanthella densities to draw attention to the potential advantages of biomass normalization in studies of coral physiology, the same volumetric arguments also should apply to the measurement of most solutes within coral tissue.

Together with published examples of variable coral biomass (cited above), the data presented here illustrate the consequences of normalizing physiological data to colony area, and suggest that similar effects may be widespread within the Scleractinia. Neither area nor biomass is "right" or "wrong" for normalizing, but there are inherent advantages (and drawbacks) to each method. In most cases, we believe that normalizing to biomass will be most effective in accounting for coral size in comparative studies, because area does not fully incorporate the intricacies of coral design (i.e., tissue and skeleton morphology) or its spatio-temporal variability (Clayton 1985). Protein provides one tractable measure of biomass (e.g., Zamer et al. 1989), although care must be taken to ensure its complete extraction from the coral skeleton and accurate quantification. Because the efficiency of removing tissue with a WaterPik ${ }^{\circledR}$ might vary inversely with tissue thickness or its penetration into a perforate skeleton, further studies are necessary to compare biomass estimates obtained with a WaterPik ${ }^{\circledR}$ with those from alternative methods, such as crushing and extracting pieces of coral skeleton (Lesser et al. 1994). Montastraea does not have a perforate skeleton, and therefore a WaterPik ${ }^{\circledR}$ probably is quite efficient at removing tissue, although we did not quantify extraction efficiency with this technique. Area still may, however, be better than biomass for normalizing processes that are, or have the potential to be, mass-transfer limited. For example, in corals with thick tissues, oxygen transfer through their surface area could limit aerobic respiration (Patterson 1992). In such cases, the effects of size on respiration would be better adjusted for by normalizing to area, preferably the actual area of the tissue. Similar reasoning also could apply to normalizing zooxanthella densities in corals with thick tissue, but with the zooxanthellae localized in the outer layer of the tissue, or to normalizing metabolites and other solutes that tend to concentrate near the outer surface of the tissue. Because surface area normalization remains the best approach for certain parameters, it will be important to develop and refine techniques - such as three-dimensional photography - to quantify the area of expanded coral tissue.

In summary, this note draws attention to the consequences of normalizing physiological data to area and biomass for scleractinian corals, and demonstrates the importance of matching the normalizing parameter to the research hypothesis and dependent variable. While there is no "correct" method, we believe that normalizing to biomass offers the greater potential to better understand, and experimentally detect, subtle variation in coral biology that could have important consequences.

Acknowledgements The impetus for this paper arose from collaborative studies between 1993 and the 2001, which made us aware of the limitations of methods for normalizing physiological data for reef corals. This research was funded, in part, by the Office of Naval Research (N00014-93-1-0440), subcontract UNCW 9801 from the University of North Carolina at Wilmington (Award no. NA66RU0132), the CSUN Research and Grants Program, and the East/West Marine Biology Program of Northeastern University. Corals were sampled in Florida under a research permit from the Florida Keys National Marine Sanctuary (FKNMS-170-97). Our Florida research would not have been possible without the collaboration of D.F. Gleason, and our research in Jamaica ben- 
efited from the help of John Bruno and Marco Calavetta. We would like to thank S. Miller and the staff at the NURC Key Largo facility for support in Florida, M. Haley and the staff at the Discovery Bay Marine Laboratory (DBML) for support in Jamaica, and many colleagues and graduate students who have assisted in this research. We are grateful to R.C. Carpenter, S.V. Vollmer, $\mathrm{K}$. Anthony, and two anonymous reviewers for comments that improved earlier drafts of this paper. This is DBML contribution number 655 .

\section{References}

Barnes DJ, Lough JM (1992) Systematic variations in the depth of skeleton occupied by coral tissue in massive colonies of Porites from the Great Barrier Reef. J Exp Mar Biol Ecol 159:113-128

Beyers RJ (1966) Metabolic similarities between symbiotic coelenterates and aquatic ecosystems. Arch Hydrobiol 62:273-284

Black NA, Voellmy R, Szmant AM (1995) Heat shock protein induction in Montastraea faveolata and Aiptasia pallida exposed to elevated temperatures. Biol Bull 188:234-240

Bradford M (1976) A rapid and sensitive method for the quantitation of microgram quantities of protein utilizing the principle of protein dye binding. Anal Biochem 72:248-254

Brown BE, Ambarsari I, Warner ME, Fitt WK, Dunne RP, Gibb SW, Cummings DG (1999a) Diurnal changes in photochemical efficiency and xanthophyll concentrations in shallow water reef corals: evidence for photoinhibition and photoprotection. Coral Reefs 18:99-105

Brown BE, Dunne RP, Ambarsari I, LeTissier MDA, Satapoomin U (1999b) Seasonal fluctuations in environmental factors and variation in symbiotic algae and chlorophyll pigments in four Indo-Pacific coral species. Mar Ecol Prog Ser 191:53-69

Bruno JF, Edmunds PJ (1997) Clonal variation for phenotypic plasticity in the coral Madracis mirabilis. Ecology 78:2177-2190

Clayton WS (1985) Polyp density variability among colonies of the reef coral Pocillopora damicornis. Bull Mar Sci 36:716-719

Davies PS (1980) Respiration in some Atlantic reef corals in relation to vertical distribution and growth form. Biol Bull 158:187-194

Edmunds PJ (1994) Evidence that reef-wide patterns of coral bleaching may be the result of the distribution of bleachingsusceptible coral clones. Mar Biol 121:137-142

Edmunds PJ, Davies PS (1986) An energy budget for Porites porites (Scleractinia). Mar Biol 92:339-347

Edmunds PJ, Gates RD, Gleason DF (2001) The biology of larvae from the reef coral Porites astreoides and their response to temperature disturbances. Mar Biol 139:981-989

Fitt WK, McFarland FK, Warner ME, Chilcoat GC (2000) Seasonal patterns of tissue biomass and densities of symbiotic dinoflagellates in reef corals and relation to coral bleaching. Limnol Oceanogr 45:677-685

Goreau TF, Goreau NI (1959) The physiology of skeleton formation in corals. I. Calcium deposition by hermatypic corals under different conditions on the reef. Biol Bull 117:239-250

Gould SJ (1966) Allometry and size in ontogeny and phylogeny. Biol Rev Camb Philos Soc 41:587-640

Hoegh-Guldberg O (1988) A method for determining the surface area of corals. Coral Reefs 7:113-116

Hughes DJ, Hughes RN (1986) Metabolic implications of modularity: studies on the respiration and growth of Electra pilosa. Philos Trans R Soc Lond 313:23-29

Jackson JBC (1979) Morphological strategies of sessile animals. In: Larwood G, Rosen BR (eds) Biology and systematics of colonial organisms. Academic Press, London, pp 499-555
Johannes RE, Wiebe WJ (1970) Method for determination of coral tissue biomass and composition. Limnol Oceanogr 15:822-824

Kanwisher JW, Wainright SA (1967) Oxygen balance in some reef corals. Biol Bull 133:378-390

Kawaguti S (1937) On the physiology of reef corals. 1. On the oxygen exchanges of reef corals. Palao Trop Biol Stn Stud 1:187-198

Kim K, Lasker HR (1998) Allometry of resource capture in colonial cnidarians and constraints on modular growth. Funct Ecol 12:646-654

Kühl M, Cohen Y, Dalsgaard T, Jorgensen BB, Revsbech NP (1995) Microenvironment and photosynthesis of zooxanthellae in scleractinian corals studied with microsensors for $\mathrm{O}_{2}, \mathrm{pH}$ and light. Mar Ecol Prog Ser 117:159-172

Lasker H (1981) Phenotypic variation in the coral Montastrea cavernosa and its effects on colony energetics. Biol Bull 160:292-302

Lesser MP, Weis VM, Patterson MR, Jokiel PL (1994) Effects of morphology and water motion on carbon delivery and productivity in the reef coral, Pocillopora damicornis (Linnaeus): diffusion barriers, inorganic carbon limitation, and biochemical plasticity. J Exp Mar Biol Ecol 178:153-179

Marsh JA (1970) Primary productivity of reef-building calcareous red algae. Ecology 51:255-263

Marshall AT (1996) Calcification in hermatypic and ahermatypic corals. Science 271:637-639

Motoda S (1940) The environment and the life of the massive reef coral Goniastrea aspera Verrill inhabiting the reef flat in Palao. Palao Trop Biol Stn Stud 2:61-104

Muscatine L, Ferrier-Pages C, Blackburn A, Gates RD, Baghdasarian G, Allemand D (1998) Cell-specific density of symbiotic dinoflagellates in tropical anthozoans. Coral Reefs 17:329-337

NOAA (2001) National environmental satellite, data and information service. http://orbit-net.nesdis.noaa.gov/orad/sub/ sst series sombreropath.html

Packard GC, Boardman TJ (1988) The misuse of ratios, indices and percentages in ecophysiological research. Physiol Zool 61:1-9

Patterson MR (1992) A chemical engineering view of cnidarian symbioses. Am Zool 32:566-582

Porter JW (1976) Autotrophy, heterotrophy and resource partitioning in Caribbean reef-building corals. Am Nat 110:731-742

Porter JW, Fitt WK, Spero HJ, Rogers CS, White MW (1989) Bleaching in reef corals: physiological and stable isotopic responses. Proc Natl Acad Sci USA 86:9342-9346

Schmidt-Nielsen K (1974) Scaling in biology: the consequences of size. J Exp Zool 194:287-308

Schmidt-Nielsen K (1984) Scaling: why is animal size so important? Cambridge University Press, Cambridge

Sebens K (1987) Coelenterata. In: Pandian TP, Vernberg FJ (eds) Animal energetics. Academic Press, New York, pp 55-120

Szmant AM, Ferrer LM, Fitzgerald LM (1990) Nitrogen excretion and $\mathrm{O}: \mathrm{N}$ ratios in reef corals: evidence for conservation of nitrogen. Mar Biol 104:119-127

Vollmer SV, Edmunds PJ (2000) Allometric scaling in small colonies of the scleractinian coral Siderastrea siderea (Ellis and Solander). Biol Bull 199:21-28

Wells JM, Wells AH, Vanderwalker JG (1973) In situ studies of metabolism in benthic reef communities. Helgol Wiss Meeresunters 24:78-81

Yonge CM, Yonge MJ, Nicholls AG (1932) Studies on the physiology of corals. VI. The relationship between respiration in corals and the production of oxygen by their zooxanthellae. Sci Rep Great Barrier Reef Exped 1928-29 1:213-251

Zamer WE, Shick JM, Tapley DW (1989) Protein measurement and energetic considerations: comparisons of biochemical and stoichiometric methods using BSA and protein isolated from sea anemones. Limnol Oceanogr 34:256-263 